\title{
The Effect of Population Aging on Heating Energy Demand on National Level: A Case Study of Slovenia
}

\author{
Žiga Lampret ${ }^{1}$ - Gorazd Krese ${ }^{2}$ - Matjaž Prek1,* \\ 1University of Ljubljana, Faculty of Mechanical Engineering, Slovenia \\ 2Korona d.d., Slovenia
}

Residential energy demands are expected to change significantly in the future with increasing electrification, energy efficiency, and improved comfort as well as climate change. While many studies have been performed into how the aforementioned influential factors could affect the energy needs of the forthcoming generations, far less are present for how population aging affects the future heating demand. The latter is particularly relevant for Europe and Slovenia as declining fertility rates and lengthening life spans give rise to the increasing ratio of the elderly.

In this paper, the future residential space and water heating energy demands of the aging society in Slovenia, using a sample of geographically dispersed nursing homes as a proxy, are estimated. The results are compared against the latest EU reference scenario until 2050, whereby the adjusted estimates differ by up to $9.6 \%$. Thus, the study highlights the need for energy policy to be further refined and redefined to link the energy performance requirements of buildings to specific consumption characteristics of the elderly.

Keywords: energy forecasting, residential energy demand, space heating, domestic hot water (DHW), aging society, base temperature

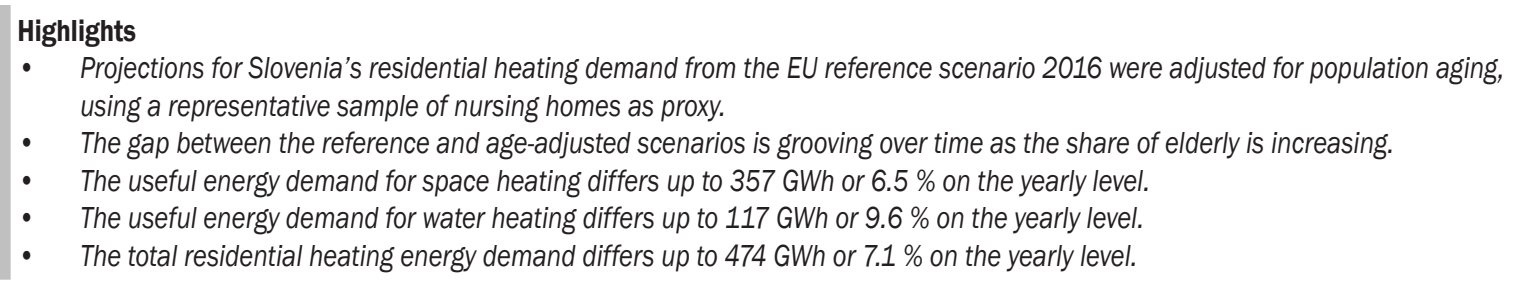

\section{INTRODUCTION}

In its 2030 Energy strategy the European Union (EU) is targeting $30 \%$ reduction of greenhouse gas emissions (GHG) compared to year 1990 (and $80 \%$ until 2050), renewable energy sources share increase to at least $27 \%$ and an energy efficiency increase of at least $27 \%$. Improvements in the energy performance of the building stock represents one of the key opportunities in achieving these goals, as buildings represent $40 \%$ of the end energy use in the EU [1] to [3]. However, in increasing the energy performance of the building stock, comfortable and quality indoor environment must not be compromised [4].

In addition to building characteristics, many studies have shown an important impact of indoor environment occupants on the residential energy demand [5] to [7]. This is especially emphasized in the case of the elderly, who usually tend to have indoor environment requirements linked to more intensive energy use. These different requirements are crucial to consider when modelling building energy use as well as when projecting future energy use [8].

The EU and other developed countries are encountering population aging, which presents a challenge in designing suitable living environment. Healthy aging is one of the main focus points of the
World Health Organization and is included in their "Aging and Health" program [9]. Since elderly spend up to $90 \%$ of the time in the indoor environment, a lot of concern is directed towards providing suitable living environments with a positive impact on their health and well-being.

Human body thermoregulation capabilities decrease with aging. Changes in the elderly thermoregulation contribute to changes in preferred indoor conditions and the ability of the human body to adapt to thermal stimuli [10]. Current thermal comfort standards and guidelines, based on the Fanger's model of thermal comfort [11], do not take into account effect of aging as they assume that different age groups do not perceive thermal environment differently. Other studies have, however, disputed that and shown that elderly prefer different optimal thermal environment conditions in comparison to younger adults. For example, Schellen et al. [12] showed that elderly group of subjects preferred warmer conditions as their younger counterparts, i.e. neutral thermal environment conditions of the younger subgroup were felt as cool by the elderly group. Similar results were obtained in [13], where the air temperature range of $20^{\circ} \mathrm{C}$ to 24 ${ }^{\circ} \mathrm{C}$, recognized as thermally comfortable by a younger group, was perceived as cool by the elderly, who expressed preference for warmer conditions. 
Role of the occupant behaviour is often neglected when it comes to building energy modelling, by excessively focusing on the technical and physical attributes of buildings [14]. When it comes to future energy demand, projections primarily focus on climate change, economic drivers and demographic pattern in terms of population size. Even though studies have found relations between residential energy demand and household occupants age [15], there is a distinct lack of qualitative and quantitative research when it comes to precise deduction of age-related effects from the stand point of occupant behaviour and differentiation of thermal environment conditions, which subsequently results in higher space heating energy demand.

The focus of this study was to assess the effect of aging on the total residential heating demand on a national level. In order to quantify the difference between the energy use patterns of the elderly and the rest of the population, a representative sample of geographically dispersed nursing homes in Slovenia was used as proxy and compared against a control group of buildings with mainly residents from younger subgroups. In order to reveal the discrepancy in preferred thermal set-points, the sample buildings were analysed with regard to their base temperature values. In addition to space heating energy demand, possible variations in domestic hot water $(D H W)$ demand were also investigated, which to our knowledge has yet to be researched from the standpoint of energy-related behavioural patterns. Finally, the results of the analysis were applied to adjust the energy demand projections for Slovenia, from the EU Reference Scenario 2016, for population aging.

\section{DATA AND METHODS}

\subsection{Baseline}

The baseline for our study represents the EU Reference Scenario 2016 (EUref2016) [16], which supports the European Commission's policy decision- making process via model-based energy system analysis until 2050 using the PRIMES energy system model [17]. In terms of modelling energy demand, the EUref2016 is analysed on sector level based on non-linear optimization routines and econometric functions [18]. Regarding useful residential energy demand, the PRIMES model uses two main drivers. Namely, number of persons per household and income per capita. Hence, the population trends are considered only in terms of projected number of residents and not in their age structure.

For our analysis, we limit ourselves only to trends for useful residential energy demand for space and water heating (see Table 1).

Table 1. EUref2016 projections for Slovenia

\begin{tabular}{|c|c|c|c|c|c|c|}
\hline Year & & 2015 & 2020 & 2030 & 2040 & 2050 \\
\hline \multirow{2}{*}{$\begin{array}{l}\text { Useful energy } \\
\text { [GWh] }\end{array}$} & Heating & 5963 & 6127 & 5455 & 5706 & 5500 \\
\hline & DHW & 1357 & 1395 & 1234 & 1277 & 1220 \\
\hline
\end{tabular}

\subsection{Demographic Trends}

One of the key drivers affecting energy demand, particularly residential, are demographic trends. In our analysis, we use population projections from Eurostat with the base year 2018, i.e. EUROPOP2018 [19]. The EUROPOP projections provide the information on future population counts for all EU countries by sex and single year of age until 2100 . We restrict our analysis to the period from 2020 to 2050 to be in line with EUref2016 (Table 2).

In our study, we use the same threshold age for the elderly as the European Commission [20], i.e. 65 , which is also the minimum required age for admittance in nursing homes in Slovenia.

\subsection{Heating Degree Days}

Degree-days are commonly used to assess the impact of climate change on the annual and seasonal trends in the energy demand for space heating and cooling as well as the resulting GHG emissions [21] to [24]. Heating degree-days $(H D D)$ are defined as sum of

Table 2. EUROPOP2018 projections for Slovenia [19]

\begin{tabular}{llcccc}
\hline Year & & 2020 & 2030 & 2040 & 2050 \\
\hline Population, January 1st & $2,083,676$ & $2,079,967$ & $2,056,567$ & $2,024,248$ \\
\hline \multirow{3}{*}{ Population [\%] } & 0 years to 14 years & 15.2 & 13.6 & 13.0 & 14.1 \\
\cline { 2 - 6 } & 15 years to 65 years & 64.5 & 61.4 & 58.5 & 54.5 \\
\cline { 2 - 6 } & 65 years and above & 20.4 & 25.0 & 28.5 & 31.3 \\
\cline { 2 - 6 } & 80 years and above & 5.5 & 6.8 & 9.8 & 11.6 \\
\hline
\end{tabular}


positive differences between a reference or base temperature and the outdoor air (dry-bulb) temperature over a certain time period:

$$
H D D=\sum_{i}\left(T_{b}-T_{o, i}\right)_{\left(\forall T_{o, i}<T_{b}\right)},
$$

where $H D D$ are heating degree-days, $T_{b}$ is the base temperature, and $T_{o, i}$ is the mean daily outdoor temperature for the $i^{\text {th }}$ day.

The base temperature represents the maximum outside temperature at which no auxiliary heating is required to maintain the thermal comfort inside the building. The base temperature depends on the building's thermal characteristics (thermal insulation and inertia), internal (people, lights, appliances and equipment) and external (i.e. solar) heat gains as well as on the set indoor temperature and, is as such, specific for each building. Thus, if possible, the base temperature should be determined individually for each building as suggested in [25] and demonstrated by [26] to [31], instead of using common values prescribed by corresponding national bodies (e.g. 15 ${ }^{\circ} \mathrm{C}$ in Germany [32] and $12{ }^{\circ} \mathrm{C}$ in Slovenia [33]). One method for determining the base temperature from monthly energy data is the so-called performance line method proposed by Day et al. [34].

Performance lines are essentially best-fit straight lines through data on scatter plots of monthly heating energy use $Q_{\text {heat }}$ against monthly $H D D_{m}$. The base temperature of a building is determined by putting a best-fit second order polynomial through data on a $H D D_{m}$ versus $Q_{\text {heat }}$ scatter plot and by varying the base until the polynomial best is almost equal to linear, i.e. the quadratic term's regression becomes zero as shown in Fig. 1.

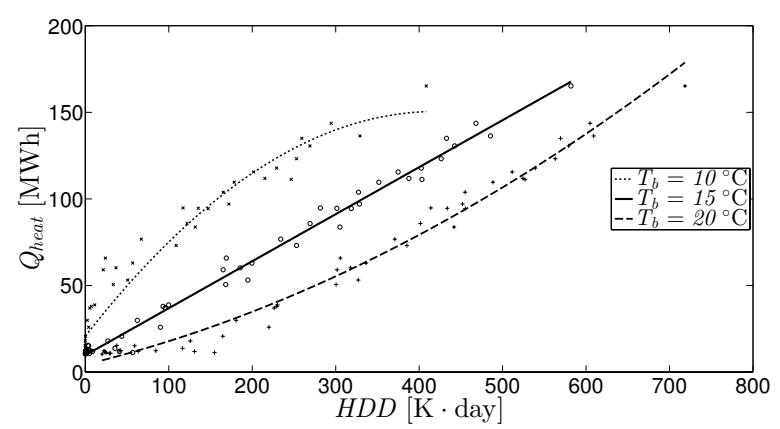

Fig. 1. Base temperature determination according to the performance line method

\subsection{Population Aging Impact}

In order to assess the effect of aging on the heating demand, a representative sample of geographically dispersed nursing homes in Slovenia (Fig. 2), i.e. representing $11.8 \%$ nursing homes nationwide, was selected as proxy.

Based on the findings of the studies reviewed in the introduction, which indicate that the elderly prefer different indoor environment parameters than other age groups, we hypothesize that the heating base temperature of buildings occupied predominantly by seniors differs significantly from comparable residences of younger subpopulations due to different set-point temperature. To evaluate this hypothesis, we selected a control group of 16 buildings with similar thermal characteristics and heating systems as well as user profiles occupied primarily by younger (i.e. student dorms) and mixed-aged groups (Table 3 ).

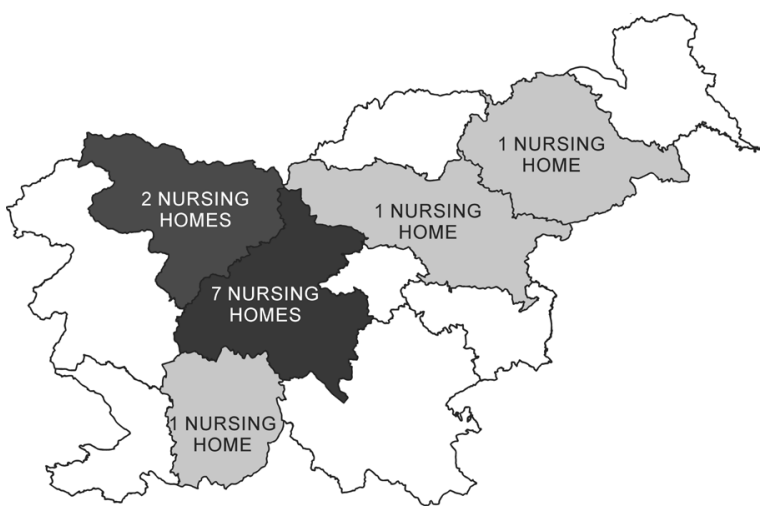

Fig. 2. Distribution of selected nursing homes according to Slovene statistical regions

For both building groups, monthly calorimeter readings (separate space heating and $D H W$ ) from 2015 to 2018 were made available, while the corresponding mean daily air temperatures were obtained from local weather stations from the Slovenian Environment Agency's database [35].

Table 3. Main building groups' characteristics - average values

\begin{tabular}{lcc}
\hline & $\begin{array}{c}\text { Proxy nursing } \\
\text { homes }\end{array}$ & $\begin{array}{c}\text { Control group } \\
\text { buildings }\end{array}$ \\
\hline Number of occupants [-] & $239 \pm 57$ & $265 \pm 72$ \\
\hline Gross net area [m²] & $6,418 \pm 2.556$ & $5,358 \pm 3.130$ \\
\hline Wall $U$-value [Wm-2 $\left.\mathrm{K}^{-1}\right]$ & $0.53 \pm 0.13$ & $0.57 \pm 0.22$ \\
\hline Window $U$-value $\left[\mathrm{Wm}^{-2} \mathrm{~K}^{-1}\right]$ & $1.71 \pm 0.65$ & $1.78 \pm 0.55$ \\
\hline Roof $U$-value $\left[\mathrm{Wm}^{-2} \mathrm{~K}^{-1}\right]$ & $0.35 \pm 0.19$ & $0.41 \pm 0.22$ \\
\hline Window - wall ratio $[-]$ & $0.127 \pm 0.59$ & $0.116 \pm 0.66$ \\
\hline Occupant density [m²/person] & $26.5 \pm 6.5$ & $20.0 \pm 7.8$ \\
\hline
\end{tabular}

The aging-adjusted space heating useful energy demand projections are then calculated as follows: 


$$
\begin{aligned}
\widehat{Q}_{\text {heat }, i}= & Q_{\text {heat }, i} \cdot\left(1-f_{\text {old }}\right)+ \\
& Q_{\text {heat }, i} \cdot f_{\text {old }, i} \cdot \frac{H D D_{i}\left(T_{b} \pm \Delta T_{b}\right)}{H D D_{i}\left(T_{b}\right)},
\end{aligned}
$$

where $\widehat{Q}_{\text {heat }, i}$ is the aging-adjusted space heating energy demand for the $i^{\text {th }}$ year, $Q_{\text {heat }, i}$ is the reference space heating energy demand for the $i^{\text {th }}$ year, $f_{\text {old }, i}$ is the elderly share of total population for the $i^{\text {th }}$ year, and $\Delta T_{b}$ is the base temperature difference between the nursing homes and the control group.

In Eq. (3), $H D D$ on a national level was calculated as a population weighted sum of $H D D$ of the 11 most populated cites in Slovenia (Appendix, Table 10), which represent $34.7 \%$ of its total population:

$$
H D D=\sum_{j} f_{j} H D D_{j},
$$

where $H D D_{j}$ is the $H D D$ value for the $j^{\text {th }}$ city, and $f_{j}$ is the population share of the $j^{\text {th }}$ city with regard to the total population of all the considered cites.

As DHW energy demand is not climate related, the following equation was used to estimate the future useful energy demand:

$$
\widehat{Q}_{D H W, i}=q_{D H W}^{y p} \cdot\left(N_{\text {tot }}-N_{\text {old }}\right)+q_{D H W}^{\text {old }} \cdot N_{\text {old }},
$$

where $\widehat{Q}_{D H W, i}$ is aging-adjusted $D H W$ preparation energy demand, $q_{D H W}^{y p}$ is the per capita $D H W$ energy demand for the non-elderly subpopulation, $q_{D H W}^{\text {old }}$ is the per capita $D H W$ energy demand for the elderly subpopulation, $N_{t o t}$ is total number of citizens, and $N_{\text {old }}$ is the number of elderly citizens.

\section{RESULTS AND ANALYSIS}

\subsection{Space Heating}

Tables 4 and 5 present base temperature values, for the selected nursing homes and the control group buildings, determined according to performance line method presented in subsection 1.3. Although the values seem quite similar at first glance, the nursing homes have on average a $1.34{ }^{\circ} \mathrm{C}$ higher base temperature, i.e. $16.76{ }^{\circ} \mathrm{C}$ versus $15.41{ }^{\circ} \mathrm{C}$ for the control group. This is in line with the studies summarized in the introduction, as seniors feel more comfortable at higher indoor temperatures.

The next step in assessing the impact of aging on space heating energy demand was to calculate the corresponding annual $H D D$. Here the question arose, which reference base temperature to select to appropriately represent Slovenia's dwelling stock, as

\begin{tabular}{|c|c|c|c|}
\hline Nursing home & $T_{b}\left[{ }^{\circ} \mathrm{C}\right]$ & Nursing home & $T_{b}\left[{ }^{\circ} \mathrm{C}\right]$ \\
\hline 1 & 16.89 & 7 & 15.78 \\
\hline 2 & 17.35 & 8 & 17.64 \\
\hline 3 & 16.95 & 9 & 17.24 \\
\hline 4 & 16.05 & 10 & 16.74 \\
\hline 5 & 15.94 & 11 & 16.45 \\
\hline 6 & 17.25 & 12 & 16.82 \\
\hline
\end{tabular}

the control building group was too small to generalize its results across the entire country.

\begin{tabular}{|c|c|c|c|}
\hline Building & $T_{b}\left[{ }^{\circ} \mathrm{C}\right]$ & Building & $T_{b}\left[{ }^{\circ} \mathrm{C}\right]$ \\
\hline 1 & 15.22 & 9 & 15.49 \\
\hline 2 & 14.45 & 10 & 16.32 \\
\hline 3 & 18.36 & 11 & 14.86 \\
\hline 4 & 16.88 & 12 & 17.50 \\
\hline 5 & 11.68 & 13 & 14.56 \\
\hline 6 & 15.88 & 14 & 15.72 \\
\hline 7 & 13.25 & 15 & 16.20 \\
\hline 8 & 14.89 & 16 & 15.37 \\
\hline
\end{tabular}

Table 4. Base temperatures of the proxy nursing homes

Table 5. Base temperatures of the control group buildings

As explained in subsection 1.3, the base temperature represents the balance temperature at which a building is in thermal equilibrium with its environment and, is as such, specific for each building. Therefore, it is not straightforward to determine a base temperature, which is representative for the entire dwelling stock on national level. For instance, the current Slovene legislation prescribes a base temperature of $12{ }^{\circ} \mathrm{C}$ [33] while Eurostat [36] as well as Germany [32] use $15^{\circ} \mathrm{C}$, which, essentially, means that the building stock in Slovenia has significantly better thermal characteristics than the average dwelling in the EU or Germany. Since this does not reflect the reality, i.e. average $U$-value of Slovene building stock $1.47 \mathrm{Wm}^{-2} \mathrm{~K}^{-1}$ compared to $1.14 \mathrm{Wm}^{-2} \mathrm{~K}^{-1}$ in Germany [37], and we did not have any data to support either of the proposed base temperature values, we decided to calculate $H D D$ with multiple base temperatures between $12{ }^{\circ} \mathrm{C}$ and $15{ }^{\circ} \mathrm{C}$ with an $1{ }^{\circ} \mathrm{C}$ increment. The resulting $H D D$, calculated for 2015 as baseline (Eq. (3)), are shown in Table 6 while the corresponding corrected space heating projections (Eq. (2)) are depicted in Fig. 3.

As seen from Fig. 3, all the corrected projections are significantly higher than EUref2016. Particularly, the gap between the reference and age-adjusted projections is growing over time as the share of elderly is increasing (Table 2). The difference is most pronounced at the scenario with the lowest $\left(12{ }^{\circ} \mathrm{C}\right)$ 
base temperature, namely, between $4.2 \%$ for 2020 and $6.5 \%$ for 2050 , and is decreasing with higher values of the reference base temperature, i.e. deviation between $3.4 \%$ and $5.3 \%$ at $15{ }^{\circ} \mathrm{C}$. The changes between the corrected scenarios depend on the yearly air temperature distribution. Specifically, climates with distinctive temperature variations between seasons are more sensitive to chosen base temperature value and vice versa for moderate climates. This has serious implications for Slovenia and Europe as, due to climate change, transition seasons are getting shorter, while temperature extremes are becoming more frequent. Moreover, as thermal characteristics of buildings are constantly improving, we can expect that the base temperature of the future residential building stock will be more towards the lower end of our scale. Hence, aging will most probably have a more severe effect on space heating energy use than our adjustments suggest.

Table 6. $H D D$ values for projections correction

\begin{tabular}{ccc}
\hline$T_{b}\left[{ }^{\circ} \mathrm{C}\right]$ & $H D D\left(T_{b}\right)[\mathrm{K} \cdot$ day $]$ & $H D D\left(T_{b}+\Delta T_{b}\right)[\mathrm{K} \cdot$ day $]$ \\
\hline 12 & 1271 & 1534 \\
\hline 13 & 1465 & 1745 \\
\hline 14 & 1672 & 1972 \\
\hline 15 & 1893 & 2211 \\
\hline
\end{tabular}

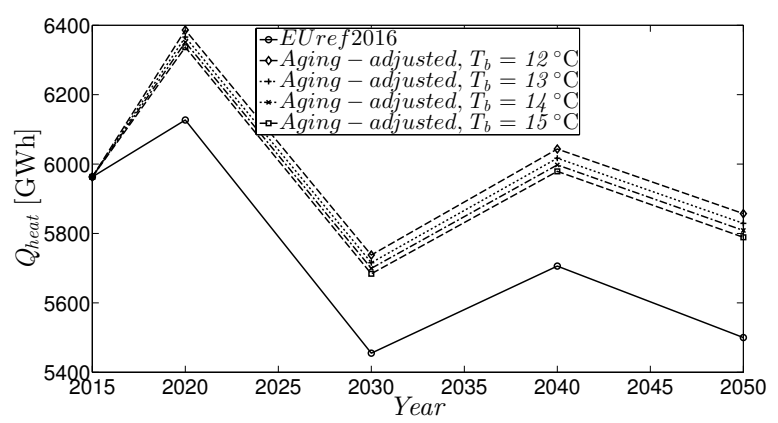

Fig. 3. Comparison of space heating energy demand projections

\subsection{Domestic Hot Water}

Contrary to space heating demand, $D H W$ demand in far less researched even though it plays an important role in the total heat demand. With increasingly more energy efficient buildings in the future its role is expected to be even more important [38].

Since $D H W$ heat demand is predominantly driven by occupant behavior [39], first, the energy use intensity variation between the selected nursing homes and the control group buildings had to be assessed (Table 7).
Table 7. DHW annual energy use parameters

\begin{tabular}{|c|c|c|c|}
\hline & \multicolumn{2}{|c|}{ Energy use intensity } & \multirow{2}{*}{$\begin{array}{c}\text { DHW share } \\
{[\%]}\end{array}$} \\
\hline & {$\left[\mathrm{kWh} / \mathrm{m}^{2}\right]$} & [kWh/person] & \\
\hline Nursing homes & 55.8 & 1497.6 & 27.7 \\
\hline Control group & 44.5 & 822.5 & 33.4 \\
\hline
\end{tabular}

Whereas the area energy use intensity of nursing homes was on average $25.2 \%$ higher compared to the control group, a much higher differentiation, i.e. $82.1 \%$, was observed in terms of energy intensity per capita. This is a consequence of the lower occupant density in nursing homes, which is also characteristic for dwellings occupied by elderly households. On the other side, the $D H W$ heat demand share was higher for the control group buildings, which is linked to the lower space heating energy demand as a consequence of lower base temperature values (Tables 4 and 5).

As the sample buildings do not represent actual dwellings, we could not directly apply the derived per capita energy intensities for the calculation of the corrected projections. Thus, Eq. (4) was modified as follows:

$$
\begin{gathered}
\hat{Q}_{D H W, i}=\frac{Q_{D H W, i}}{N_{t o t, i}} \cdot\left(N_{t o t, i}-N_{\text {old }, i}\right)+ \\
\frac{Q_{D H W, i}}{N_{t o t, i}} \cdot\left(\frac{q_{D H W}^{n h}}{q_{D H W}^{c g}}\right) \cdot N_{\text {old }, i},
\end{gathered}
$$

where $Q_{D H W, i}$ is the reference $D H W$ energy demand for the $i^{\text {th }}$ year, $q_{D H W}^{n h}$ is the average per capita $D H W$ energy demand of the proxy nursing homes, and $q_{D H W}^{c g}$ is the average per capita $D H W$ energy demand of the control group buildings.

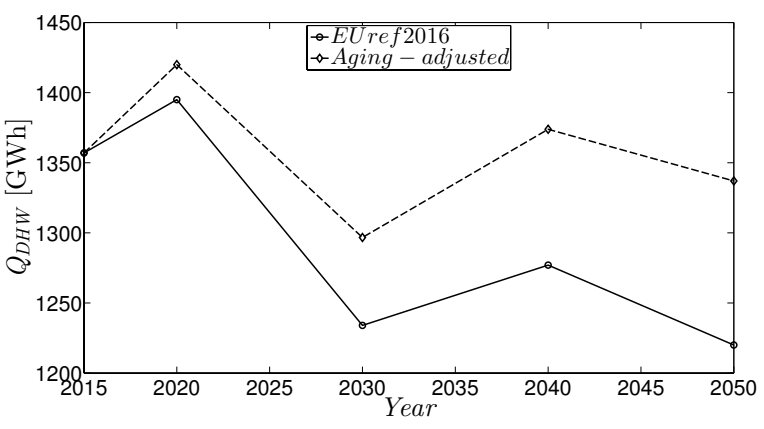

Fig. 4. Comparison of DHW energy demand projections

As was the case with space heating, the corrected projections for $D H W$ are higher in comparison to the EUref2016 projections (Fig. 4). The discrepancy increases with years at a significantly higher rate as the gap at space heating projections, i.e. from $1.8 \%$ in year 2020 , to $9.6 \%$ in year 2050 . The reasons for this lies in the decreasing $D H W$ energy intensity per capita 
of the reference scenario (Table 8), which contradicts the recent trends [38].

Table 8. DHW per capita energy intensity of the EUref2016 scenario

\begin{tabular}{llllll}
\hline & 2015 & 2020 & 2030 & 2040 & 2050 \\
\hline$\frac{Q_{D H W, i}}{N_{\text {tot }, i}}[\mathrm{kWh} /$ person $]$ & 658 & 669 & 593 & 621 & 603 \\
\hline
\end{tabular}

\subsection{Total Heating Demand}

As indicated in subsection 2.1, we expect that the base temperature of buildings will decrease in the future. Therefore, for the total heating energy demand estimates only space heating projections, calculated with the lowest base temperature, were considered and summed together with the corresponding $D H W$ projections from section 2.2.

As expected from the space and water heating results, the difference between the reference and aging-adjusted scenario increases together with the elderly share (Fig. 5), i.e. from $3.8 \%$ or $284 \mathrm{GWh}$ in 2020 to $7.1 \%$ or $474 \mathrm{GWh}$ in 2050 .

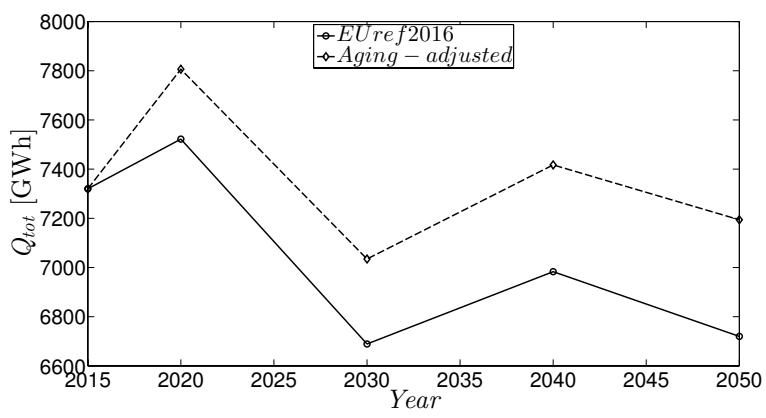

Fig. 5. Comparison of total heating energy demand projections

Particularly, the scenario gap is very similar as at space heating projections, since the latter represents a large majority of the total heating demand, namely from $81.8 \%$ in 2020 and $81.4 \%$ in 2050 . This is not in line with the current trends, as the share of $D H W$ in total heat requirement of new energy-efficient buildings is documented around $40 \%$ to $50 \%$ [40], although the impact of $D H W$ is growing over the years (Table 9). This implies that the EUref2016 scenario, on which our corrections are based on, does not fully account for the thermal performance improvement of the building stock, envisioned by corresponding regulatory bodies, e.g. [41]. Furthermore, the reference scenario also does not consider the recent findings of increasing $D H W$ consumption per capita [39], since it foresees a declining specific water heating demand, as already indicated in the previous subchapter (Table 8).
Table 9. The effect of DHW on the scenario gap

\begin{tabular}{lcccc}
\hline & 2020 & 2030 & 2040 & 2050 \\
\hline$\Delta Q_{D H W} / \Delta Q_{\text {tot }}[\%]$ & 8.8 & 18.1 & 22.3 & 24.7 \\
\hline
\end{tabular}

\section{CONCLUSIONS}

This paper presents a methodology for adjusting heating energy demand projections on a national level for population aging. The method is based on using heating energy measurements from a representative sample of real-life nursing homes as proxy. In this study, the data representing $11.8 \%$ of nursing homes in Slovenia was used to adjust its foreseen residential heating energy demand according to the EUref2016 scenario.

In order to assess the effect of aging on the space heating demand, we determined the base temperature values of the observed nursing homes and compared them against a control group of buildings. The base temperature differed on average for $1.34{ }^{\circ} \mathrm{C}$, which resulted in a projection deviation from $210 \mathrm{GWh}$ to $357 \mathrm{GWh}$ or $3.8 \%$ to $6.5 \%$, respectively. This difference, basically, represents the discrepancy between the set-point temperatures of the elderly and the rest of the population, due to changes in the elderly thermoregulation. Hence, it implies that aging may nullify the positive effects of global warming on heating demands, as countries committed to the 2015 Paris Agreement (including Slovenia) strive to limit the temperature increase to $1.5{ }^{\circ} \mathrm{C}$ above preindustrial levels. Furthermore, as the base temperature of the future dwelling stock is expected to decrease due to improved thermal performance of buildings, the discovered set-indoor temperature gap and with it population aging will most probably have a more severe effect on space heating energy use than our results imply.

On the other hand, the climate-unrelated $\mathrm{DHW}$ energy demand projections varied between $1.8 \%$ and $9.6 \%$ from the baseline scenario, whereby the gap is increasing over time as the foreseen share of seniors is growing. Contrarily, $\mathrm{DHW}$ 's share in the total heat requirement remains fairly stagnant over the future, at around $18 \%$, i.e. significantly lower than the sample buildings (Table 7). This contradicts the recent trends of the rising importance of water heating in the residential energy balance, which implies that the EUref2016 unsatisfactory accounts for the currently increasing $\mathrm{DHW}$ consumption per capita as well as the envisioned thermal performance improvement of the building stock. 
Regarding the total heating energy demand, our aging-adjusted projections differ between $3.8 \%$, in 2020 , and $7.1 \%$, in 2050, from the reference values for Slovenia. This results in an annual difference up to $474 \mathrm{GWh}$, which is more than the yearly energy production of small hydro power plants and almost twice of the annual generation of photovoltaic power plants in Slovenia in 2018 (i.e. 425.9 GWh and 259.1 GWh [42]). Hence, this discrepancy may have farreaching implications for Slovenia's (sustainable) energy planning as well as for achieving its climate targets.

These results, however, should be interpreted with caution due to the assumptions and simplification made in this study. The most obvious simplification is that seniors admitted to nursing homes share the same energy usage patterns as independently living elderly, which currently represent more than $95 \%$ of Slovenes aged 65 and above. This is especially critical when observing single-detached dwellings, as elderly households are typically smaller and, hence, a larger living area per capita must be heated to maintain thermal comfort, which implies that population aging may have a more profound effect on the residential energy balance than our research suggests. Thus, our study should be expanded to annual monitoring of energy use and energy-related behavioral patterns of dwellings occupied primarily by seniors as well as a reference group consisting of younger subpopulations. Here, the monitoring should be performed at least on an hourly basis, in order to discover potential deviations between daily energy profiles of different age groups, as this may become particularly important in light of the increasing electrification of the residential energy demand. Further research directions also include the effect of aging on the future space cooling energy demand as well as investigating possible interdependencies with energy poverty, since income of the elderly is generally decreasing with increasingly less sustainable pension systems all across Europe, which is again a consequence of population aging.

\section{ACKNOWLEDGEMENTS}

The work was funded by the Slovenian Research Agency (ARRS) via research funding for young researchers.

\section{REFERENCES}

[1] European Commission (2002). Directive 2002/91/EC of the European Parliament and of the Council of 16 December
2002 on the energy performance of buildings. Official Journal of the European Union, p. 65-71.

[2] EU (2010). Directive 2010/31/EU of the European Parliament and of the Council of 19 May 2010 on the energy performance of buildings (recast). Official Journal of the European Union, p. 13-35.

[3] Ivanovski, I., Goričanec, D., Salamunić, J.J., Žagar, T. (2018). The comparison between two high-temperature heat-pumps for the production of sanitary water. Strojniški vestnik - Journal of Mechanical Engineering, vol. 64, no. 7-8, p. 437-442, DOl:10.5545/sv-jme.2017.5082.

[4] Dovjak, M., Slobodnik, J., Krainer, A. (2019). Deteriorated indoor environmental quality as a collateral damage of present day extensive renovations. Strojniški vestnik Journal of Mechanical Engineering, vol. 65, no. 1, p. 31-40, DOl:10.5545/sv-jme.2018.5384.

[5] van Dronkelaar, C., Dowson, M., Spataru, C., Mumovic, D. (2016). A review of the regulatory energy performance gap and its underlying causes in non-domestic buildings. Frontiers in Mechanical Engineering, vol. 1, p. 1-14, D0l:10.3389/ fmech.2015.00017.

[6] International Energy Agency (2013). Total Energy Use in Buildings - Analysis and Evaluation Methods. International Energy Agency (IEA), Sendai, Japan.

[7] Wei, S., Jones, R., de Wilde, P. (2014). Driving factors for occupant-controlled space heating in residential buildings. Energy and Buildings, vol. 70, p. 36-44, Dol:10.1016/j. enbuild.2013.11.001.

[8] Yu, B., Wei, Y.M., Kei, G., Matsuoka, Y. (2018). Future scenarios for energy consumption and carbon emissions due to demographic transitions in Chinese households. Nature Energy, vol. 3, p. 109-118, D0I:10.1038/s41560-017-0053-4.

[9] Ormandy, D., Ezratty, V. (2012). Health and thermal comfort: from WHO guidance to housing strategies. Energy Policy, vol. 49, p. 116-121, D0I:10.1016/j.enpol.2011.09.003.

[10] Blatteis, C.M. (2012). Age-dependent changes in temperature regulation - a mini review. Gerontology, vol. 58, p. 289-295, Dol:10.1159/000333148.

[11] Fanger, P.0. (1970). Thermal Comfort: Analysis and Applications in Environmental Engineering. Danish Technical Press, Copenhagen.

[12] Schellen, L., van Marken Lichtenbelt, W.D., Loomans, M.G.L.C., Toftum, J., de Wit, M.H. (2010). Differences between young adults and elderly in thermal comfort, productivity, and thermal physiology in response to a moderate temperature drift and a steady-state condition. Indoor Air, vol. 20, p. 273283, Dol:10.1111/j.1600-0668.2010.00657.x.

[13] Hwang, R.L., Chen, C.P. (2010). Field study on behaviors and adaptation of elderly people and their thermal comfort requirements in residential environments. Indoor Air, vol. 20, p. 235-245, D0l:10.1111/j.1600-0668.2010.00649.x.

[14] Estiri, H., Zagheni, E. (2019). Age matters: Ageing and household energy demand in the United States. Energy Research and Social Science, vol. 55, p. 62-70, D0l:10.1016/j. erss.2019.05.006.

[15] Deutsch, M., Timpe, P. (2013). The effect of age on residential energy demand. ECEEE 2013 Summer Study Proceedings, p. 2177-2188. 
[16] Capros, P. (2016). EU Reference Scenario 2016, Energy, Transport and GHG Emissions Trends to 2050. EU Commission, Brussels.

[17] E3MLab (2018). Primes model version 2018: Detailed model description. National Technical University of Athens, Athens.

[18] Herbst, A., Reiter, U., Rehfeldt, M. (2017). Benchmarking the EU reference scenario 2016: An alternative bottom-up analysis of long-term energy consumption in europe. ECEEE 2017 Summer Study Proceedings, p. 159-169.

[19] Eurostat (2018). Europop2018: European population projections 2018-based, from https://ec.europa.eu/ eurostat/web/population-demography-migration-projections/ population-projections-data, accessed on 2019-10-22.

[20] European Commission (2014). Population Ageing in Europe: Facts, Implications and Policies. European Commision, Brussels.

[21] D'Amico, A., Ciulla, G., Panno, D., Ferrari, S. (2019). Building energy demand assessment through heating degree days: The importance of a climatic dataset. Applied Energy, vol. 242, p. 1285-1306, DOI:10.1016/J.apenergy.2019.03.167.

[22] Berger, M., Worlitschek, J. (2019). The link between climate and thermal energy demand on national level: A case study on Switzerland. Energy and Buildings, vol. 202, ID 109372, D0I:10.1016/j.enbuild.2019.109372.

[23] Jakubcionis, M., Carlsson, J. (2017). Estimation of European Union residential sector space cooling potential. Energy Policy, vol. 101, p. 225-235, D0I:10.1016/J.enpol.2016.11.047.

[24] Streicher, K.N., Padey, P., Parra, D., Bürer, M.C., Schneider, S., Patel, M.K. (2019). Analysis of space heating demand in the Swiss residential building stock: Element-based bottom-up model of archetype buildings. Energy and Buildings, vol. 184, p. 300-322, D0I:10.1016/j.enbuild.2018.12.011.

[25] Day, T. (2006). Degree-Days - Theory and Application TM41: 2006. The Chartered Institution of Building Services Engineers, London.

[26] Day, A.R. (2005). An improved use of cooling degree-days for analysing chiller energy consumption in buildings. Building Services Engineering Research and Technology, vol. 26, p. 115-127, D0I:10.1191/0143624405bt1250a.

[27] Layberry, R. (2008). Degree days for building energy management - presentation of a new data set. Building Services Engineering Research and Technology, vol. 29, p. 273-282, DOI:10.1177/0143624408093886.

[28] Karlsson, J., Roos, A., Karlsson, B. (2003). Building and climate influence on the balance temperature of buildings. Building and Environment, vol. 38, p. 75-81, D0l:10.1016/ S0360-1323(02)00025-2.

[29] Krese, G., Prek, M., Butala, V. (2011). Incorporation of latent loads into the cooling degree days concept. Energy and Buildings, vol. 43, p. 1757-1764, D0l:10.1016/j. enbuild.2011.03.042.

[30] Hitchin, R., Knight, I. (2016). Daily energy consumption signatures and control charts for air-conditioned buildings. Energy and Buildings, vol. 112, p. 101-109, Dol:10.1016/j. enbuild.2015.11.059.

[31] Krese, G., Lampret, Ž., Butala, V., Prek, M. (2018). Determination of a building's balance point temperature as an energy characteristic. Energy, vol. 165, p. 1034-1049, Dol:10.1016/j.energy.2018.10.025.

[32] VDI 2067-1 (2012). Economic Efficiency of Building Installations (Fundamentals and Economic Calculation). Verein Deutscher Ingenieure (VDI), Düsseldorf.

[33] Ministry for Infrastructure RS (2015). Rules on Dividing and Billing Heating Costs in Multiple-Dwelling and Other Buildings with Several Units. Ministry for Infrastructure, Republic of Slovenia, Ljubljana.

[34] Day, A.R., Knight, I., Dunn, G., Gaddas, R. (2003). Improved methods for evaluating base temperature for use in building energy performance lines. Building Services Engineering Research and Technology, vol. 24, no. 4, p. 221-228, DOl:10.1191/0143624403bt0730a.

[35] Slovenian Environment Agency (2019). Meteo.Si - national

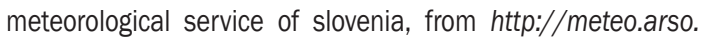
gov.si/met/en/, accessed on 2019-10-12.

[36] Eurostat (2019). Energy statistics - cooling and heating degree days, from $h$ ttps://ec.europa.eu/eurostat/cache/metadata/ en/nrg-chdd/esms.htm, accessed on 2019-10-12.

[37] European Commission (2019). EU buildings database, from https://ec.europa.eu/energy/en/eu-buildings-database, accessed on 2019-10-22.

[38] Yang, X., Li, H., Svendsen, S. (2016). Energy, economy and exergy evaluations of the solutions for supplying domestic hot water from low-temperature district heating in denmark. Energy Conversion and Management, vol. 122, p. 142-152, DOl:10.1016/j.enconman.2016.05.057.

[39] Marszal-Pomianowska, A., Zhang, C., Pomianowski, M., Heiselberg, P., Gram-Hanssen, K., Rhiger Hansen, A. (2019). Simple methodology to estimate the mean hourly and the daily profiles of domestic hot water demand from hourly total heating readings. Energy and Buildings, vol. 184, p. 53-64, D0I:10.1016/J.enbuild.2018.11.035.

[40] Erhorn, H., Erhorn-Kluttig, H. (2014). Selected examples of nearly zero- energy buildings. EASME, Brussels.

[41] European Commission (2018). Energy performance of buildings directive (EU) 2018/844. EU Official Journal (L156), vol. 276 LNCS, p. 17.

[42] Energy Agency of the Republic of Slovenia (2018). Report on the energy sector in Slovenia 2018. Energy Agency of the Republic of Slovenia, Maribor. (in Slovene)

[43] Statistical Office of the Republic of Slovenia (2019). Sistat database, from https://pxweb.stat.si/SiStat/en, accessed on 2019-10-15.

\section{APPENDIX}

Table 10. Population size of the 11 largest municipalities in Slovenia in 2015 [43]

\begin{tabular}{|c|c|c|c|}
\hline City & Population size & City & Population size \\
\hline Ljubljana & 287,347 & Velenje & 32,736 \\
\hline Maribor & 111,735 & Novo Gorica & 31,771 \\
\hline Kranj & 56,108 & Ptuj & 23151 \\
\hline Koper & 51,053 & Murska Sobota & 18,935 \\
\hline Celje & 48,901 & Slovenj Gradec & 16,758 \\
\hline Novo mesto & 36,344 & $\Sigma$ & 714,839 \\
\hline
\end{tabular}

